\title{
Quando a reformulação é uma remodalização com efeito de atenuação
}

\author{
WHEN REFORMULATION IS REMODALIZATION WITH ATTENUATION EFFECT \\ Helena Topa Valentim \\ Universidade Nova de Lisboa / Centro de Linguística da Universidade Nova de Lisboa \\ Resumo:
}

De um ponto de vista funcional a reformulação é metadiscursiva (Briz, 1998). O controle metadiscursivo sobre a produção do sentido implica, por parte do locutor, um comportamento cooperativo motivado pelo desejo de esclarecer possíveis equívocos e de superar obstáculos comunicacionais, pelo que se compreende que, muitas vezes, possa resultar num efeito de atenuação. Além da dimensão discursiva, a reformulação tem também um estatuto semântico. Na atividade de enunciar a reformulação opera no âmbito de uma relação de pertinência entre "o dizer" e "o querer dizer".

Este artigo enquadra-se teoricamente na teoria de operações predicativas e enunciativas (TOPE), segundo a qual enunciar é, antes de mais, um processo que se reconstrói a partir do enunciado enquanto encadeamento de formas; ou seja, é o produto de operações de determinação de diferentes ordens que intervêm na construção do enunciado. Também de acordo com este modelo, a modalização de qualquer enunciado constitui uma dessas ordens de determinação do enunciado. São as operações de modalização que determinam a relação predicativa no que respeita ao grau e à forma como o sujeito enunciador o valida. O estudo da modalização inclui o fenómeno da remodalização, que consiste na "passagem de um valor modal a outro valor modal diferente, incidindo duas ou mais operações de modalização sobre a mesma relação predicativa. A segunda operação desconstrói o valor construído pela primeira." (Campos, 1997: 158)

Partindo da observação de ocorrências de construções de reformulação em que se dá uma remodalização com um efeito discursivo de atenuação, proceder-se-á à descrição formal das operações subjacentes a estes fenómenos, procurando mostrar que estamos perante fenómenos que atestam diferentes níveis do funcionamento da linguagem aqui paradigmaticamente evidenciando uma relação de interdependência teórica. Deste modo, é possível descrever certos casos de atenuação 
enquanto construção de um segundo valor modal, situado numa escala de valores assertivos e numa relação com um primeiro valor modal, desta feita reformulado. Por conseguinte, mais do que se sobreporem, os fenómenos de reformulação, remodalização e atenuação estão numa relação de interdependência, comprometendo inclusive as fronteiras que ditam os domínios tradicionais do funcionamento da linguagem: o discursivo, o pragmático, o gramatical.

Palavras-chave: reformulação, modalidade, remodalização, atenuação, gramática, léxico

\section{Abstract:}

From a functional point of view, reformulation is metadiscursive (Briz, 1998). The metadiscursive control over the production of meaning implies a cooperative behavior on the part of the speaker motivated by the desire to clarify possible misunderstandings and to overcome communication obstacles. This is the reason why it can often have an attenuation effect. Besides the discursive dimension, the reformulation also has a semantic status. In the activity of enunciating reformulation operates within a relation of pertinence between "the saying" and "the wanting to say".

The approach here proposed is based in the theory of predicative and enunciative operations (TOPE), according to which to enunciate is first of all a process that is reconstructed from the utterance as a chain of forms. In other words, the utterance is the product of operations of different orders determination. Also according to this theoretical framework, the modalization of any utterance is one of these orders of enunciative determination. The predicative relation (or propositional content), with respect to the degree and to the way the subject enunciator validates it, is determined through the operations that underlie modalization. That's why the study of the modalization includes the phenomenon of the remodalization, which consists of "passing from one modal value to another different modal value, focusing two or more modalization operations on the same predicative relation. The second operation deconstructs the value constructed by the former. "(Campos, 1997: 158)

The observation of occurrences of reformulation in which remodalization presents a discursive effect of attenuation leads to a formal description of the operations underlying these phenomena, showing that they have to do with different levels of language functioning even if they paradigmatically evidenciate a relation of theoretical interdependence. Thus, we intend to demonstrate how it is possible to describe certain cases of attenuation as a construction of a second modal value, situated on the scale of assertive values and in a relation with a first modal value, the one reformulated. Therefore, rather than overlapping one the other, the phenomena of reformulation, remodalization and attenuation are in a relation of interdependence, compromising the boundaries that dictate the traditional domains of the functioning of language: the discursive, the pragmatic, the grammatical.

KEYWORDS: Reformulation, Modality, Remodalization, Attenuation, Grammar, Lexicon 
Em termos de relações discursivas e conversacionais, isto é, de um ponto de vista funcional. a reformulação é metadiscursiva; tem a ver, portanto, com a construção discursiva (Briz, 1998). Resulta do controle metadiscursivo sobre a produção do sentido, implicando, por isso, por parte do locutor, um comportamento cooperativo motivado pelo desejo de esclarecer possíveis equívocos e de superar obstáculos comunicacionais (Pons, 2000). É deste modo que se compreende que, muitas vezes, possa resultar da reformulação um efeito de atenuação.

Quanto à remodalização, é naturalmente um fenómeno enquadrado no domínio mais amplo da construção da categoria modal das línguas, ou modalização. A modalização, como fenómeno enunciativo de construção de valores semânticos, explica-se num quadro segundo o qual enunciar é, antes de mais, um processo que se reconstrói a partir do enunciado enquanto encadeamento de formas; ou seja, em que o enunciado é o produto de operações de determinação de diferentes ordens. Encontramos esta conceção de enunciar e de enunciado (enquadradoras, portanto, da modalização) no modelo teórico de operações predicativas e enunciativas (TOPE). Assim, de acordo com este modelo, a modalização de qualquer enunciado constitui uma das categorias de determinação. Em particular, são as operações de modalização que determinam a relação predicativa, ou conteúdo proposicional, no que respeita ao grau e à forma como o sujeito enunciador o valida e assume, em termos epistémicos, apreciativos e intersujeitos (Campos, 2001).

Consequentemente, o estudo da modalização inclui o fenómeno da remodalização, que consiste na "passagem de um valor modal a outro valor modal diferente, incidindo duas ou mais operações de modalização sobre a mesma relação predicativa. A segunda operação desconstrói o valor construído pela primeira." (Campos, 1997: 158).

A atenuação, como a intensificação, constituem na tradição dos estudos linguísticos fenómenos de natureza sobretudo pragmática (desde o primeiro momento, Briz, 1995, 1997 e 1998; veja-se o projecto dito de "análisis sociolingüístico y pragmático de la atenuación", in Briz \& Albelda, 2013). Recordemos, por exemplo, que o Princípio de Cooperação (Grice) e as máximas que o regem induzem a um comportamento "regrado", controlado e, por isso, podemos dizer que "atenuado" dos interlocutores. Desta constatação decorre o facto de se poder considerar que o fenómeno da cortesia se pode manifestar através de recursos que servem para atenuar (Escandell Vidal, 1996). Mesmo se Briz (1998: 158) assinala que a cortesia é um fenómeno eminentemente sociológico e não estritamente linguístico (comportamento que depende de normas sociais, ou regras normativas e não regras constitutivas, segundo Searle), as estratégias de atenuação que lhe subjazem não deixam de ser consideradas, por este e outros autores, como eminentemente pragmáticas. 


\section{ATENUAÇÃO E REFORMULAÇÃO - GRAMÁTICA E SEMÂNTICA}

Sabemos que, tanto no tratamento do fenómeno da reformulação como no da atenuação, o seu caráter eminentemente discursivo e pragmático não invalida que se lhes reconheça uma base dita "gramatical e/ou lexical", referida pelos diferentes autores, nomeadamente quando identificam formas linguísticas que dizem ser formas "marcadoras" da construção dos fenómenos em causa. Quanto à reformulação, a sua natureza, seja parafrástica seja não parafrástica, é assinalada, segundo os diferentes autores (Roulet, 1987: 115; Rossari, 1994; Noren, 1999), por formas linguísticas particulares, os chamados reformuladores. São, normalmente, designadas como conectores ou marcadores discursivos, que, ora marcam uma relação de reformulação parafrástica, ao assinalarem seja a repetição seja a equivalência (Zorraquino \& Portolés, 1999: 4124), como, por exemplo, ou seja, isto é, por outras palavras; ora marcam uma relação de reformulação não parafrástica, que resulta ora numa reconsideração, ora num distanciamento ou mesmo numa rejeição da perspectiva explanada na sequência precedente (Rossari, 1990), com, por exemplo, melhor dito, ou antes, ou ainda em todo o caso, de qualquer maneira, em qualquer caso, na realidade, no fundo.

Esta bipartição é, porém, questionável uma vez que, por implicar sempre uma distância. Como se propõe em Pons (2013), a reformulação não acarreta uma igualdade textual ou comunicativa, nem lhe subjaz a construção de uma mesma coisa do ponto de vista nocional ou semântico: "reformular no es establecer una paráfrasis" (ibidem: 157).

Quanto ao fenómeno pragmático da atenuação, é comum o reconhecimento de que, como todo o fenómeno pragmático, a descrição da atenuação baseia-se na identificação de formas gramaticais e lexicais. Portolés (1998), por exemplo, ao falar de marcadores discursivos atenuativos releva a sua filiação em categorias morfo-sintáticas, a saber advérbios e conjunções. Inclui igualmente outras formas como bueno, hombre ou mujer, que sendo adjetivo e nomes, funcionam como marcadores pragmáticos. Os atenuantes, como os intensificadores, são, de acordo com a literatura disponível, recursos morfológicos, sintáticos e lexicais, ao serviço de um objetivo comunicacional que dita o seu caráter estratégico.

No entanto, há uma questão que emerge destas considerações. O que se entende por "gramática", ou marcação linguística, neste movimento teórico geral de se reconhecer a relevância da marcação linguística para a descrição, seja de fenómenos discursivopragmáticos (a reformulação e a atenuação, no caso)? De acordo com as reflexões que citei, podemos tender para uma resposta segundo a qual a gramática é o repositório classificatório de formas, já que é enquanto conjunções, advérbios, nomes, adjetivos, que se diz que estas marcam as operações de relevância discursiva (a reformulação) e/ou pragmática (a atenuação).

Através de uma descrição de uma produção linguística atestada, pretendo exatamente questionar e ultrapassar esta perspetiva, relevando o estatuto semântico-enunciativo da reformulação e da atenuação, estatuto que poderá redimensionar o entendimento da base 
gramatical destes fenómenos ditos discursivos e pragmáticos, ao impor um entendimento operatório do funcionamento da linguagem em detrimento de um critério classificatório (estritamente morfo-sintático).

\section{ESTUDO DE UM CASO}

Partamos de um dos exemplos atestados em que reconhecemos um efeito argumentativo de atenuação. Trata-se de um enxerto de uma entrevista de transmissão televisiva: entrevista de Judite de Sousa a Assunção Cristas, sobre nova lei das rendas. TVI, 29-12-2011)

JS: (sobre definição de "situação de carência") Um casal de 80 anos que vivam os dois sozinhos com pensão mínima é uma situação de carência?

AC: Com certeza. Nesses casos posso-Ihe garantir que não haverá provavelmente atualização nenhuma [da renda].

O nosso enfoque recai naturalmente na sequência que, na dinâmica conversacional, constitui a resposta à pergunta formulada pela entrevistadora. Em termos de determinação modal, a sequência de abertura, "com certeza", marca a construção de um valor modal epistémico do domínio do certo. O enunciador valida o conteúdo proposicional que é pré-construído pelo enunciador da pergunta total "Um casal de 80 anos que vivam os dois sozinhos com pensão mínima é uma situação de carência?". Mais propriamente, "com certeza" marca um reforço dessa validação assertiva - está na base do que, sob o ponto de vista pragmático, será uma intensificação, no caso, de um valor modal epistémico.

Na sequência subsequente, a predicação "posso-lhe garantir" incide, enquanto estrutura subordinante, sobre um conteúdo proposicional, ao nível da subordinada - "não haver [...] actualização nenhuma [da renda]". Parafrasearíamos esta sequência subordinante por "estou em condições de lhe garantir", o que pragmaticamente redunda na realização de um ato de fala promissivo (de acordo com Austin e também Searle): dizer "posso-lhe garantir" é dizer "garanto-Ihe"; esta sequência realiza um ato promissivo explícito.

Já ao nível da estrutura subordinada, ocorre uma remodalização, isto é, a "passagem de um valor modal a outro valor modal diferente" (Campos, 1997: 158). A forma "provavelmente" marca a construção de um valor assertivo mitigado, a validação do conteúdo proposicional pelo enunciador não é total; trata-se de um valor de possibilidade.

Incidem, portanto, sobre o mesmo conteúdo proposicional - "não haver [...] actualização nenhuma [da renda]" - duas operações de modalização que são, por definição, exclusivas. A segunda operação desconstrói a primeira (Campos, 1997) e não o contrário, em função de uma orientação discursiva ditada pela ordem cronológica das produções linguísticas. 
Este caso de remodalização configura uma reformulação discursiva: opera-se, no dizer de Rosari (1994: 17), "une hiérarchisation subsumante ("avec changement de perspective énonciative") entre le point de vue qu'il introduit (reformulation) et le point de vue auquel il renvoie.". A reformulação aqui construída visa um efeito atenuativo, já que "provavelmente" reduz, ou atenua, a força ilocutória do ato de fala promissivo.

O estatuto reformulativo desta sequência seria, de acordo com o "critério gramatical"(ou critério de marcação linguística) questionável, já que não é identificável qualquer forma linguística, qualquer conector que sinalize a natureza da reformulação. Não podemos, porém - penso - deixar de reconhecer que estamos perante uma reformulação. Da mesma forma, a atenuação aqui reconhecível - passagem de um valor de asserção estrita, e reforçada, para um valor de asserção mitigada, isto é, para um valor intermédio na escala de valores assertivos (Campos, 1997) carece da presença de um atenuador gramaticalmente (entenda-se, morfosintaticamente) identificável.

O valor epistémico marcado por "provavelmente" releva aqui da ordem do dizer, não da ordem dos factos. O mesmo é dizer que é um valor de possibilidade, não de probabilidade. Essa especificidade decorre do contexto reformulativo, que dita uma atenuação pragmática. Vimos, aliás, que, neste caso, os "termos" formulado e reformulado não são predicativos; são lugares enunciativos, formas de o enunciador validar epistemicamente o conteúdo proposicional, tendo isto consequências pragmáticas: por esta via, um ato promissivo previamente realizado é "revisto" uma vez diminuída a sua força ilocutória.

Como, então, entender a construção gramatical que motiva a reformulação discursiva e a atenuação pragmática?

Em primeiro lugar, só encarando a deformabilidade das formas, isto é, só no quadro de uma variabilidade de valores para os quais contribuem todas as formas em coocorrência, assim como o contexto - por exemplo, naquilo que respeita a prática social enquadradora da interacção que permite configurar géneros textuais diferentes - no caso, entrevista televisiva em que o entrevistado é um governante, tem poder executivo. Em segundo lugar, tendo presente que as formas linguísticas, enquanto marcadoras destes fenómenos, não valem meramente em função da sua classificação morfo-sintática ou do seu estatuto gramatical ou lexical; valem enquanto marcadoras de operações enunciativas subjacentes, de ordem mais profunda, cognitiva.

\section{O ESTATUTO DA REFORMULAÇÃO E DA ATENUAÇÃO NA ATIVIDADE DE ENUNCIAR: RELAÇÃO ENTRE "O DIZER" E "O QUERER DIZER"}

A reformulação linguística, como a atenuação, são, como qualquer outro fenómeno de ajustamento intersubjetivo, manifestação evidente de uma das dimensões da atividade da linguagem: a regulação intersubjetiva. Além das abordagens discursiva e pragmática (ou mesmo, para entender e sustentar estas abordagens), não deixa, no entanto, de ser 
importante considerar que qualquer produção linguística, naquilo que sejam opções lexicais ou outras imputadas a um locutor em função do uso pragmático-discursivo, passa por uma construção e por uma validação enunciativas, a que, por sua vez, presidem dimensões de representação cognitiva e de construção de referência.

Nesse sentido e numa perspetiva semântico-enunciativa, os fenómenos de reformulação e de atenuação não se prendem apenas com questões de adequação em função de certa prática discursiva. Atestam também a forma como a linguagem é uma atividade de representação de noções definidas por propriedades físico-culturais, variáveis portanto, do mesmo modo que demonstra que a linguagem permite construir valores referenciais ancorados nas coordenadas espácio-temporal e subjetiva da situação de enunciação.

É assim que, além das dimensões discursiva e pragmática, a reformulação e a atenuação têm também um estatuto semântico. Na atividade de enunciar, a reformulação e a atenuação operam no âmbito de uma relação de pertinência entre "o dizer" e "o querer dizer". São fenómenos linguísticos suscetíveis de ser explicados sob um ponto de vista do funcionamento da linguagem conforme o modelo proposto no quadro da TOPE. De forma particular, prestase a uma reflexão com base na definição que em Culioli se dá (reiteradamente e de várias formas) da atividade de enunciar, como processo que se reconstrói a partir do enunciado enquanto encadeamento de formas.

Partamos da definição de asserção proposta por Culioli (2001: 280), assim sintetizável:

"je tiens à dire (= rendre public) que je pense / crois / sais que p est le cas".

Em Paillard (2010), "desmonta-se" esta formulação, explicitando os dois âmbitos que aqui se articulam. Refere-se que esta definição se centra, por um lado, no sujeito, por outro, no estatuto do dizer. Tem-se, respetivamente:

a) uma definição centrada no sujeito: o sujeito empenha-se / implica-se, constrói o espaço intersubjectivo (rend public), define a sua relação com o dizer (de uma subjectividade pura - je pense - a uma verdade estabelecida - je sais);

b) uma definição do estatuto do dizer: $p$ est le cas é o produto de um cálculo que passa pela selecção e uma sequência p em relação a um estado de coisas a dizer (ce qui est le cas).

Assim, à partida, não há uma relação necessária entre $p$ e o à dire: $p$ é selecionado entre outras sequências possíveis suscetíveis de exprimir o estado de coisas, isto é, (p,p'). É porque o enunciado é um entre outros que este modelo permite dar conta da reformulação, parafrástica ou não parafrástica, assim como da atenuação, enquanto fenómenos que explicitam esta alteridade em que os próprios enunciados se inscrevem, ou seja, como recurso a outro enunciado que não $p$ (distinto de $p$ ). É nesta medida também que à seleção de $p$ está associada uma posição subjetiva ( $\left.\mathrm{S}_{0}\right)$. 
Por conseguinte, não se deve resumir o conteúdo ao que é efetivamente dito: de facto, nada garante que "o que é dito" corresponde ao que seja o "querer dizer", só assim se explicando a operação subjacente à sequência modalmente posicionada no polo da asserção estrita "posso garantir que") e a sequência marcadora de um valor modal de asserção não total (ou mitigada) "provavelmente". Na verdade, outras formas linguísticas seriam possíveis. Nada garante, portanto, que as formas empregues sejam as adequadas ao "querer dizer", que sejam pertinentes. Da mesma forma, nada garante que o coenunciador, no seu trabalho de interpretação, interprete este "querer dizer" como o enunciador.

Assim se explica, a um nível cognitivo, a operação primitiva que funda os fenómenos de reformulação e de atenuação: a relação entre "o dizer" e "o querer dizer". Assim se percebe que as formas linguísticas, enquanto marcadoras destes fenómenos, valham não meramente em função da sua classificação morfo-sintática ou do seu estatuto gramatical ou lexical; mas também enquanto marcadoras de operações enunciativas subjacentes. No exemplo em apreço, a reformulação aí reconhecível com efeito atenuatório é descritível no que seja a sua base gramatical (a sua marcação linguística) como decorrendo de uma operação enunciativa de remodalização, que - vimos - se prende com o grau de validação do conteúdo proposicional por parte do sujeito enunciador.

Estando em causa, neste exemplo, uma reformulação não parafrástica com efeito atenuador, o princípio gramatical - entenda-se, da ordem do funcionamento da linguagem - aqui ilustrado é a relação de alteridade de qualquer "dizer" (o "dito") com outros "dizer" (outros "ditos"), e que viabiliza um entendimento da reformulação e da atenuação enquanto fenómenos de ajustamento intersubjetivo.

Uma vez que o "motor" da reformulação e da atenuação é a dimensão plural do "dizer", dirse-á que ambos os fenómenos relevam da dimensão da pertinência. A questão da pertinência, na sua relação com a reformulação e com a atenuação, atualiza precisamente esta propriedade que o "dizer" tem de não poder ser dito em definitivo, de ser sempre um falhanço na tentativa de dizer o mundo, ilustrando, no limite, o facto de a linguagem não decalcar o mundo na representação que dele construa. Neste sentido, pertinência interpreta-se, portanto, como o facto de se validar epistemicamente um determinado conteúdo proposicional sob marcação das formas "posso-lhe garantir" ou "provavelmente", enquanto construções subjetivas, que estão sempre numa relação fraca (não necessária, portanto) com o estado de coisas. Dito de uma forma curta, direta e sem "aparto" metalinguístico: dizemos sempre o que nos convém.

\section{CONCLUSÃO}

Assim, e em jeito de conclusão desta breve reflexão, os fenómenos de reformulação e de atenuação são susceptíveis de ser explicados fora dos critérios morfo-sintáticos e lexicais, podendo, por conseguinte, ser explicados sob um ponto de vista do funcionamento da linguagem, assim como ilustram, enquanto mecanismos de ajustamento intersubjetivo, vários 
princípios subjacentes à atividade linguística. Simultaneamente, uma explicação da reformulação que privilegie a dimensão semântica da linguagem nos termos aqui propostos permite colocar o problema da delimitação do fenómeno da reformulação, reforçando a pertinência de uma revisão da distinção entre reformulação parafrástica e reformulação não parafrástica e, como se propõe em Pons (2013), podendo constituir mais um argumento a favor da distinção entre reformulação e paráfrase.

\section{REFERÊNCIAS BIBLIOGRÁFICAS}

BRIZ, A. (1995): «La atenuación en la conversación coloquial. Una categoría pragmática», en Cortés, Luis (ed.), El español actual. Actas del / Simposio sobre análisis del discurso oral. Almería, Ediciones Universidad de Almería.

BRIZ, A. (1997): "Los intensificadores en la conversación coloquial», en Briz, A; Gómez Molina, J. R.; Martínez Alcalde, M. J. y grupo Val. Es. Co. (ed.), Pragmática y gramática del español hablado. El español coloquial, Zaragoza, Pórtico, 13-36.

BRiz, A. (1998): El español coloquial en la conversación: Esbozo de pragmagramática. Barcelona, Ariel Lingüística.

CAmpos, Maria Henriqueta Costa (2001): «Enunciação mediatizada e operações cognitivas». In A. S. Silva (org.) Linguagem e cognição. A perspectiva da linguística cognitiva, APL, UCP-Faculdade de Filosofia, Braga, 325340.

Campos, Maria Henriqueta Costa (1997): Tempo, Aspecto e Modalidade. Estudos de Linguística Portuguesa, Porto Editora, Porto.

CULIOLI, Antoine (2001): «Heureusement», en Mateus, M. H. M.; Correia, C. N. (orgs.) Saberes no tempo - Homenagem a Maria Henriqueta Costa Campos, Edições Colibri, Lisboa, 279-284.

ESCANDELL VIDAL, M. V. (1996): Introducción a la Pragmática, Barcelona, Ariel Lingüística.

Fuchs, Catherine (1994): Paraphrase et énonciation, Ophrys, Paris / Gap.
KeRBRAT-ORECCHIONI, Catherine (2005): Le discours en interaction, Armand Colin, Paris.

PAILLARD, Denis (2010): «Marqueurs discursifs et scène énonciative", en Hancil, S. (éd.) Connecteurs discursifs, Presses Universitaires de Rouen, Rouen, 13-39.

PONS, Salvador (2013): «Un solo tipo de reformulación", Cuadernos AISPI, 2, 151-170.

Pons, Salvador (2000): "Los Conectores", ¿Cómo Se Comenta Un Texto Coloquial?», en Briz, Antonio (eds) Grupo Val.Es.Co. Ariel, Barcelona, 198-230.

RossaRI, Corrine (1994): Les opérations de reformulation, Peter Lang, Bern.

ROULET, Eddy (1987): "Complétude interactive et connecteurs réformulatifs". Cahiers de linguistique française, 8, 111-140.

VALENTIM, Helena Topa (2013): «Diferentes valores e empregos de Isto é: uma proposta de descrição enunciativa». Estudos Linguísticos / Linguistic Studies 8, Colibri, Lisboa, 297-308.

VALENTIM, Helena Topa; GonçALVES, Matilde (2011): «Da 'descabelada que só arranja problemas' à 'mentecapta que mormente arranja problemas': encenação de reformulação não parafrástica e ficcionalização genérica», en Gonçalves, Matilde (org.), $11^{\circ}$ Cadernos WGT. Oficina de trabalho, Centro de Linguística da Universidade Nova de Lisboa - Faculdade de Ciências Sociais e Humanas, Lisboa, 43-56.

http://www.clunl.edu.pt/resources/docs/grupos/gra matica/11wgt/4\%20helena_matilde_11wgt.pdf 


\title{
Atenuação em entrevistas do projeto NURC
}

\author{
ATTENUATION IN INTERVIEWS OF NURC PROJECT
}

\author{
Luiz Antônio da Silva \\ Universidade de São Paulo/Brasil
}

Resúmen:

Quando interagimos, há uma série de elementos que são importantes para o sucesso ou fracasso da interação, pois, em geral, locutor e interlocutor procuram salvaguardar a imagem que cada um deseja que o outro considere. Mais ainda, quando interagimos, negociamos e, dependendo do que dizemos, teremos ou não sucesso no que pretendemos. Para minimizar possíveis efeitos negativos de atos que possam causar prejuízos à interação, fazemos uso de determinadas estratégias conversacionais que têm a função de regular a relação interpessoal e social dos interactantes (Briz, 1995). São elementos que suavizam, mitigam, reparam, escondem a verdadeira intenção do locutor (Briz, 2007). Dessa forma, nosso objetivo é fazer algumas considerações a respeito das estratégias de atenuação na interação entre entrevistador e entrevistado, em um inquérito do projeto NURC, seguindo a metodologia da Ficha Técnica, elaborada pelos pesquisadores do Projeto ES.POR. Atenuación.

Palavras-chave: atenuação, cortesia, imagem, interação

Abstract:

When we interact, there are a number of elements that are important for the success or failure of the interaction, since, in general, the speaker and the interlocutor seek to protect the face that each one wants to consider. Moreover, when we interact, we negotiate and, depending on what we say, we will or will not succeed in what we want. In order to minimize possible negative effects of acts that may cause harm to the interaction, we use certain conversational strategies that have the function of regulating the interpersonal and social relationship of the interactors (Briz, 1995). They are elements that soften, mitigate, repair, and hide the real intention of the speaker (Briz, 2007). Thus, our objective is to make some considerations about attenuation strategies in the interaction between interviewer and 
interviewee, in an investigation of NURC project, following the methodology of the Technical Data Sheet, elaborated by the researchers of the ES.POR. ATENUCIACIÓN Project.

KEYWORDS: attenuation, politeness, face, interaction.

\section{INTRODUCÃO}

No Brasil, a partir da década de 1970, houve um avanço significativo nos estudos sobre língua falada, especialmente com a chegada dos estudos englobados pela Sociolinguística e pela Análise da Conversação. Na esteira desses novos recortes teóricos surgiram diversos projetos, entre eles o NURC, Norma Urbana Falada Culta. Tal projeto foi implantado nas cinco capitais mais populosas (para a época) do Brasil: Recife, Salvador, Rio de Janeiro, São Paulo e Porto Alegre. Depois de um período de coleta de corpus, seguiu-se uma longa discussão sobre a análise desse valioso material para se estudar o português falado no Brasil.

Na segunda metade da década de 80, houve um grande avanço nos estudos de língua falada, consequência dos estudos levados a cabo pela equipe do Projeto NURC/SP, coordenada pelo Prof. Dr. Dino Preti. Inicialmente, foram estudos referentes a transcrições; em seguida, deu-se início à análise do corpus de língua falada, não mais seguindo os parâmetros da língua escrita, mas considerando as novidades e os avanços permitidos pelos novos recortes teóricos apresentados pelos investigadores da Análise da Conversação.

Inúmeros trabalhos de grau foram redigidos com base nos materiais do Projeto NURC/SP. As demais equipes, incentivadas pelos pesquisadores de São Paulo, deram início a um volume considerável de trabalhos sobre o português falado culto no Brasil.

Ainda que o corpus já esteja defasado em termos de sincronia, tem servido de base para trabalhos inovadores e atuais em relação aos mecanismos da língua falada.

Conscientes desse aspecto, utilizamos inquéritos do Projeto NURC/BR, do tipo DID, isto é, Diálogos entre Informante e Documentador (entrevistas). O objetivo central deste trabalho é mostrar duas vantagens na utilização da metodologia do Projeto ES.POR.ATENUACIÓN no que diz respeito aos mecanismos de atenuação, empregados por informantes, cuja língua materna é o português do Brasil.

\section{CORTESIA, ATENUAÇÃO E TRABALHO DE FACE}

Em português, o termo atenuar está relacionado ao sentido de tornar tênue, amolecer, perder a força ou intensidade, enfraquecer, reduzir, limitar, suavizar, diminuir, mitigar. Neste trabalho, o sentido de atenuar não será diferente, mas importa relacioná-lo às conhecidas teorias sobre interações sociais, especialmente aquelas que privilegiam a cortesia verbal. 
Goffman (1970) estudou diversos rituais de interação e, para ele, nem sempre, os interlocutores se acham situados em uma mesma hierarquia social ou desempenham um mesmo papel na interação, por isso, quando se entra em contato com outra pessoa, existe a preocupação de preservar a auto-imagem pública. A essa auto-imagem pública, Goffman denomina face. Trata-se da imagem pública do indivíduo, delineada em termos de atributos sociais.

Em uma interação, é possível que a imagem que o interlocutor deseja ver manifesta não se concretize, provocando, por isso, uma situação de conflito. Goffman utiliza o termo face work (trabalho de face), para designar as ações efetuadas por uma pessoa, a fim de conseguir que o que faça seja coerente com sua imagem. O trabalho de face serve para neutralizar incidentes, isto é, fatos que coloquem em risco a face do locutor ou do interlocutor. Há uma orientação defensiva, no sentido de preservar a própria face e uma orientação protetora, visando a preservar a face do outro.

O simples contato com um interlocutor já representa o rompimento de um equilíbrio, ameaçando a imagem tanto do locutor quanto do interlocutor. Isso leva a um acordo tácito entre as partes: um não ameaça a face do outro até o momento em que a própria face não é ameaçada. Todavia é preciso tomar cuidado, pois, no ímpeto de preservar a própria face, corre-se o risco de ameaçar a face do interlocutor. Ou ainda, no intuito de preservar a face do outro, é possível ameaçar a própria face.

Brown e Levinson (1978/87) ${ }^{1}$, partindo do conceito proposto por Goffman, ampliaram a noção de face. Para eles, face compreende a auto-imagem pública que todo membro da sociedade deseja reclamar para si próprio, constituindo-se de dois aspectos básicos e relacionados: face positiva e face negativa.

- Face positiva: refere-se ao desejo de que a auto-imagem seja aprovada e valorizada. É o desejo de aprovação social; refere-se à necessidade que todo indivíduo tem de ser aceito, de ser tratado como membro de um grupo, de saber que seus próprios desejos são compartilhados pelos interlocutores.

- Face negativa: refere-se à necessidade que todo indivíduo tem de ser independente, de ter liberdade de ação e de não sofrer imposição. Envolve a contestação básica aos territórios, reservas pessoais e direitos; em outras palavras, a liberdade de ação e liberdade de sofrer imposição; o desejo que as pessoas têm de não serem controladas.

Aos atos que ameaçam a face dos interactantes, os autores chamam face threatening acts, ou FTAs. Os atos de fala, chamados por Searle (1976) diretivos, invadem o território pessoal

\footnotetext{
${ }^{1}$ Os referidos autores publicaram, inicialmente, um trabalho em 1978. Em 1987 foi publicado outro texto com as modificações. Para simplificar a citação, passaremos a citar apenas a obra de 1987.
} 
do interlocutor, limitando a liberdade de ação: ordens, proibições, conselhos, pedidos, perguntas. Em outras palavras, esses atos de fala ameaçam a face negativa do interlocutor. Por meio de um ato diretivo, o locutor busca conseguir que seu interlocutor "faça coisas". Segundo Brown e Levinson, esses atos, a priori, representam uma ameaça à face negativa do interlocutor. Dessa forma, o documentador do Projeto NURC precisa ter tato ao formular as perguntas, pois, do contrário, poderá colocar em risco o objetivo da ação: fazer com que o informante fale e fale de acordo com os objetivos do momento e daquela proposta.

De outra forma, o locutor ameaça a face positiva do interlocutor quando põe em risco sua auto-estima, por exemplo, por meio de críticas, reprovações, insultos, injúrias e discordâncias. Assim, o documentador do projeto NURC terá cuidado, especialmente, quando precisará mudar de assunto ou discordar de alguma colocação feita pelo informante, a fim de não colocar em risco o equilíbrio da interação e, com isso, deixar de levar a bom termo a sua tarefa.

Com efeito, quando utilizamos atos de fala que possam ameaçar o equilíbrio da interação, é possível usar alguns recursos para minimizar as ações dos FTAs. São os chamados elementos atenuadores. Assim, a atenuação na linguagem responde à necessidade do homem de proteger-se frente a tudo aquilo que pode representar uma ameaça. Puga Larraín (1997:1415) acrescenta:

Existe uma relação inversa entre o grau de certeza que o falante tem de poder conseguir uma resposta favorável de seu interlocutor e o grau de atenuação com que ele formula seu enunciado. A menor certeza de conseguir uma resposta desejada, maior necessidade de atenuar o ato de fala em questão. Assim, a ordem e o pedido são atos que, por excelência, requerem o uso de atenuação.

A cortesia é um princípio de regulação social das interações. Tal atividade social está regulada por convenções culturais, a partir das quais um comportamento linguístico pode ser entendido como cortês ou descortês. A atenuação pode ser uma das estratégias de cortesia utilizada pelos interactantes, sempre com a finalidade de manter o equilíbrio das relações sociais.

Fraser (1980:342) afirma que a atenuação se caracteriza como uma tentativa " de reduzir a aspereza ou hostilidade da força das ações de uma pessoa”. Dessa forma, as estratégias de atenuação têm por finalidade minimizar os efeitos negativos de um ato ilocutório, reduzindo ou eliminando possíveis conflitos que podem levar a um desequilíbrio na interação social.

A atenuação, segundo Fraser (1980:343), não é sinônimo de cortesia, embora possam ocorrer num mesmo enunciado. Ao passo que a primeira envolve uma redução no efeito indesejado, a estratégia de cortesia depende da adequação do enunciado ao contexto, isto é, depende de que os participantes da conversação cumpram o estabelecido no decorrer da interação. Opondo-se à atenuação, o autor define, então, um enunciado cortês nestes termos: "podemos dizer que uma enunciação é cortês à medida que o locutor, na opinião do interlocutor, não tenha violado os direitos ou obrigações que estão tendo efeito naquele momento" (Fraser, 1980: 343-344).

Rosa (1992:28) salienta que é difícil separar os conceitos de cortesia (polidez) e atenuação: 
No caso da presença de atenuadores, certamente é difícil distinguir entre os dois conceitos (o de polidez e o de atenuação), pois o efeito de sentido resultante do enunciado parece apontar para a vinculação funcional do que é polido e do que é atenuado. (...) Apesar da dificuldade apontada, a polidez é, sem dúvida, um fenômeno mais vasto que a atenuação, podendo prescindir dos chamados procedimentos ou elementos atenuadores. Embora nem toda estratégia de polidez indique a tentativa de evitar ou diminuir a responsabilidade pelo que é dito, em alguns casos, o simples cuidado que todo locutor apresenta com a própria face suger tal motivação.

Meyer-Herman (1984:175-176) assevera que a atenuação marca estrategicamente uma tentativa de aproximação e de mais intimidade do locutor com o interlocutor, em um determinado contexto situacional:

Atenuação é uma função interactiva dum acto comunicativo a (contendo meios de atenuação) graças à qual - comparado com um acto comunicativo á menos atenuado, que este seja realizado concretamente no contexto ou seja hipotético (realizável) - os participantes da interacção aceitam e/ou estabelecem menos obrigações do que pelo acto comunicativo á.

Briz (1994) considera a atenuação como uma categoria semântico-pragmática, baseada no princípio geral da cortesia, ainda que desta seja, apenas, uma de suas estratégias. O referido autor descreve a atenuação como estratégia conversacional que suaviza a força ilocutiva de uma ação e como um "recurso estratégico dentro da atividade argumentativa e conversacional que busca a aceitação do ouvinte, seja do dito, seja do dizer, ou do próprio falante (Briz, 2005:53).

\section{Briz (2005:56) assim conceitua atenuação:}

A atenuação, como estratégia pragmalinguística, é uma operação linguística estratégica de minimização do dito, vinculada à atividade argumentativa e de negociação do acordo, que é o fim último de toda conversação. Mitigar, suavizar, diminuir a força ilocutiva, reparar, esconder a verdadeira intenção são objetivos práticos da atenuação.

Em outro estudo sobre atenuação, Briz (2007:11-12) traz outro conceito:

A atenuação, de acordo com o que há em vários trabalhos, é uma categoria pragmalinguística, cuja função consiste em minimizar a força ilocutiva dos atos de fala e o papel dos participantes da enunciação, com a finalidade de conseguir a meta prevista, o acordo (ou em mitigar o desacordo), que é o fim último ou primeiro, de acordo com a visão, de toda conversação. Diminuir, suavizar, mitigar, reparar, esconder a verdadeira intenção são valores que descrevem, de forma mais concreta, esta operação linguística estratégica vinculada à atividade argumentativa e de negociação do referido acordo que, às vezes, é também social, de imagem cortês.

Soares (1996:57) lembra que o uso de marcadores de atenuação resulta quase sempre de uma escolha estratégica do locutor:

O que acontece é que o locutor, mediante um balanço calculado e cuidadoso das necessidades do ouvinte, tem a possibilidade de as negociar na interacção conversacional num esforço de diminuir a distância social e aumentar a solidariedade para com este. O falante regula, pois, a sua interacção de maneira a atender em especial às necessidades de (1) respeitar o seu interlocutor nos seus direitos de independência, privacidade e decisão (respeitar a sua face negativa) e de (2) ser solidário com os seus sentimentos, desejos, opiniões (neste caso, respeitar a sua face positiva). Para atingir este objectivo, o enunciador pode seleccionar entre os meios linguísticos disponíveis os marcadores de reforço ou de de atenuação que considera mais apropriados à consecução dos seus objectivos. 
Puga Larraín (1997:42) acrescenta que a atenuação é um gesto de tomar distância, um recurso que separa o falante do interlocutor, porque busca preservar a face e não invadir o território alheio. A atenuação verbal serve para salvaguardar a imagem social e a auto-imagem dos interlocutores. Seu funcionamento está submetido a um funcionamento eufemístico. Por exemplo, para evitar uma palavra tabu, costuma-se recorrer a um substituto eufemístico que serve para atenuar o conteúdo proposicional.

O emprego de estratégias de atenuação resulta de uma escolha estratégica do locutor. "Por isso, os enunciados que contêm esses dispositivos são formulações linguísticas, nas quais vazam os objectivos ilocutórios do sujeito enunciador, e possuem uma força comunicativa adequada à situação em curso" (Soares, 1996:57).

Puga Larraín (1997:14) lembra que existe uma relação inversa entre o grau de certeza que o locutor tem de poder conseguir uma resposta favorável de seu interlocutor e o grau de atenuação com que the dirige a pergunta. A menor certeza de conseguir uma resposta desejada, corresponde uma maior necessidade de atenuar o ato de fala em questão. Cremos que essa relação norteia, em geral, a interação entre documentador e informante nos inquéritos, do tipo DID, do Projeto NURC/BR.

Em síntese, a atenuação refere-se à modificação de um ato de fala, que pode vir a causar efeitos indesejados sobre o interlocutor. Trata-se, portanto, da função interativa de um ato de fala, que possibilita o acordo ou a negociação em situações que possam representar possível quebra do equilíbrio em uma dada interação social.

Ainda que os três termos - atenuação, cortesia e face - possam estar interligados, Briz (2007) lembra que a presença de um não implica, necessariamente, a presença de outro. Em outras palavras, é possível que, em um ato de fala, haja atenuação, cortesia e trabalho de face, entretanto é possível, também, haver atenuação sem que haja cortesia e trabalho de face.

A título de ilustração, seguem três exemplos do Projeto NURC.

(1) Doc.: (quais as horas... que você vê...) em que você ouve rádio? (Inq.121, NURC/Porto Alegre, p.21)

(2) Doc.: bom... sobre alimentação aí... o que que você tem visto que pode dizer pra gente? (Inq.328, NURC/Rio de Janeiro, p.135)

(3) Doc.: quais os cursos que o senhor fez até chegar à universidade? (Inq.006, NURC/Porto Alegre, p.193)

Esses exemplos ilustram atos diretivos dos documentadores do projeto NURC. A função do documentador é fazer que os informantes falem o mais espontaneamente possível e com o mínimo de interferência possível. A situação em que se dá a gravação transcorre, sempre, em clima de tranquilidade e cordialidade. Em princípio, não haveria necessidade de qualquer 
elemento de atenuação nos atos diretivos dos documentadores (aqui, referimo-nos às perguntas feitas pelo documentador ao informante), pois, de antemão, os informantes sabem que estarão expostos a perguntas, a fim de colaborarem com um projeto que estuda a linguagem falada culta. Os três exemplos ilustram casos de perguntas diretas, mas o segundo e o terceiro já apresentam elementos linguísticos que têm em vista a minimização da imposição. No segundo exemplo, o Documentador busca atenuar a imposição por meio do marcador de início bom e por meio do verbo que dá possibilidades e alternativas ao interlocutor (pode). No terceiro, o Documentador busca atenuar o ato diretivo por meio da forma de tratamento formal o senhor. Por causa da cordialidade que caracteriza a situação, é muito comum o uso de táticas de atenuação, com a finalidade de preservar a face dos interactantes.

\section{ANÁLISE DO CORPUS}

Em 2012, no Congresso Cortesia, realizado em Lisboa, apresentamos um trabalho sobre as perguntas iniciais dos documentadores no início das entrevistas do NURC (Trata-se dos atos diretivos a que nos referimos na seção anterior.). Nesse trabalho, foi possível perceber que, dos trinta e quatro inquéritos analisados, apenas três não apresentaram procedimentos de atenuação. Isso nos leva à conclusão de que, no geral, há uma preocupação em minimizar o ato diretivo. Chegamos à conclusão de que há uma grande preocupação em ser ou parecer cortês, atenuar ou mitigar a imposição das perguntas, pois há um determinado grau de imposição do documentador em relação ao informante, pois estes são profissionais que disponibilizam seu tempo para se deslocarem e colaborarem com os investigadores do Projeto.

Depois da apresentação do trabalho em 2012, houve significativos avanços no Projeto ES.POR.ATENUACIÓN, especialmente no que diz respeito à metodologia, com a publicação da Ficha Técnica (Briz, 2014; Albelda et al., 2014).

Passamos, a seguir, a expor duas vantagens ao se utilizar a metodologia da Ficha Técnica:

\subsection{Evitar generalizações}

Um risco que se corre, quando se trabalha com o tema da atenuação é tirar conclusões precipitadas e fazer generalizações equivocadas. Em geral, a expressão eu acho que corresponde a uma tática atenuadora, porém é preciso analisar caso a caso e não tirar conclusões precipitadas, pois há situações em que a referida expressão é um elemento atenuador e, em outras situações, não. Para isso, consideremos os três exemplos a seguir.

(4) Doc: e:: tu achas que alguma vez o rádio assim pode:: se constituir um fator de atrito e de briga? Inf.: por causa eh um quer ouvir um programa e outro quer outro? eu acho que sim... Inquérito 121 - NURC/RS p.27

Nesse fragmento, a expressão "eu acho que" não pode ser considerada um atenuador, pois não se trata de um elemento enunciado com a intenção de mitigar a força ilocutiva do 
enunciado, mas refere-se, simplesmente, a uma resposta coordenada com a pergunta do Documentador. Este perguntou "tu achas" e o entrevistado respondeu "eu acho que sim.

(5) Doc.: e os programas humorísticos qual é que tu gostas de alguns por quê:: Inf.: olha atualmente eu acho que estão abaixo da crítica os programas humorísticos antigamente eu assistia aquele Praça da alegria o Golias as:: hoje não tem programa bom... ahn:: tem um... por exemplo... o:: hoje tem (como é que é)... tem o Caça não... eh... Balança mas não cai mas são... piadas tão bestas e... sei lá o o o nível acho que está tão baixo que não dá mais pra assistir... antes a gente ficava... alegre se alegrava tu via o programa tu te distraía hoje.. não sei não não... não vejo... mais por que assistir... esses programas

Inquérito 121 - NURC/RS p.2

Neste caso, o entrevistado está assumindo uma opinião bem particular sobre os programas humorísticos encontrados na TV brasileira e uma opinião bem ácida a respeito de tais programas. Dessa forma, por causa da opinião bem crítica e negativa, a fórmula "eu acho que" protege a autoimagem do informante. Trata-se de um recurso para salvaguardar a imagem do entrevistado que é convocado a emitir uma opinião e a emite de forma polêmica.

Outro equívoco bastante comum é considerar todo e qualquer enunciado com a forma diminutiva como uma tática atenuadora. É possível que seja, no entanto, há necessidade de se analisar com propriedade caso a caso.

(6) Doc.: (quanto às profissões) libeRAls o senhor acha que no Brasil há um desequilíbrio numérico de umas em relação a outras?

Inf.: (...) então o que há:: o que existe atualmente é isso é a ausência de um estudo... ah:: o desnivelamento numérico não se poderia acho eu cogitar porque:: sem esse primeiro estudo de mensuração não se sabe dizer se tem ou não tem advogados demais ou se tem médicos ou:: ou:: dentistas de menos... é meio difícil de dizer...

Inquérito 8 - NURC/RS p.50

Observe-se que, neste caso, a expressão aparece deslocada no sintagma. Conforme as observações de Briz (2013), não há dúvida de que, quando a expressão aparece deslocada, exerce, claramente, função atenuadora. O entrevistado não deseja transparecer segurança a respeito de sua observação sobre o número excessivo de advogados no Brasil. Sendo assim, por meio da expressão deslocada "acho eu", deixa evidente que não está seguro a respeito da afirmação de que há um número excessivo de formandos em Direito no Brasil. Trata-se de uma construção "acotadora" da opinião do entrevistado e deixa claro que a opinião não é geral, mas de quem enuncia, diminuindo, portanto, a responsabilidade do que é dito.

(7) Doc.: (quanto às profissões) libeRAls o senhor acha que no Brasil há um desequilíbrio numérico de umas em relação a outras?

(Inq.08, NURC/Porto Alegre, p.49)

Ao usar o marcador de opinião ("acha"), o documentador busca atenuar a força ilocutiva de seu ato diretivo, dando certa liberdade ao interlocutor ao elaborar a resposta. Em outras palavras, o locutor dá alternativas a seu interlocutor, diminuindo a força impositiva do ato de fala. Repare-se que, se a pergunta fosse enunciada de forma direta - No Brasil, há um desequilíbrio numérico de umas em relação a outras? -, o informante poderia, simplesmente, responder, sinteticamente, sim ou não, frustrando as expectativas do documentador, pois a 
pergunta é, apenas, uma motivação para levar o informante a falar. Rosa (1992:45) ressalta que Brown e Levinson (1987) estudam as expressões verbais de opinião ou como hedges dirigidos à máxima de qualidade de Grice, já que modificam o grau de verdade do enunciado a que se referem ou como hedges da força ilocutória.

(8) Doc.: e que tipos de rádios têm assim aqui na tua casa?

Inf.: olha tem esse tem rádio de pilha e rádio:: elétrico... rádio... EU ando sempre com radinho de pilha...

inclusive quando... eh vinha lavar roupa qualquer coisa no tanque aí então levava meu radinho aqui a minha mãe dizia que eu parecia uma lavadeira ((risos))...

Inquérito 121- NURC/RS p.24

No português do Brasil, a forma diminutiva é um recurso bastante efetivo para atenuar. É necessário, contudo, analisar o contexto em que aparece a forma diminutiva. Neste caso, a forma "radinho" é um termo neutro, pois, na época, era comum se referir aos rádios de pilha, por causa do tamanho, como "radinhos". Dessa forma, neste caso, a forma diminutiva não representa uma tática atenuadora.

(9) Doc.: você gosta de futebol?

Inf.: gosto... eu adoro futebol...

Doc.: então fale um pouquinho sobre futebol...

Inquérito 12 - NURC/RJ p.35

Neste fragmento, o exemplo é retirado da fala do documentador, que faz uma pergunta ao entrevistado a respeito do tema futebol. Repare-se que o ato de fala do Documentador é um ato diretivo, pois impõe ao entrevistado uma tarefa: falar sobre futebol. Saliente-se que o Documentador ignora se o entrevistado entende ou não do assunto abordado. Sendo assim, o uso do diminutivo serve para minimizar a imposição do pedido para falar sobre futebol. Tratase,portanto, de uma tática atenuadora.

\subsection{Utilização do contexto interacional imediato}

Na Ficha Técnica do Projeto ES.POR.ATENUACIÓN, há uma orientação clara, sem o que o analista chegará a conclusões equivocadas: a necessidade de considerar o contexto interacional geral e o contexto interacional específico. O contexto geral focaliza o ambiente físico e social que cerca o ato de comunicação. O contexto interacional específico é fundamental para o analista, pois é possível que o contexto sofra alguma interferência no ato de comunicação. Por exemplo, uma interação que envolva uma conversa entre marido e mulher revela envolvimento mais estreito e imediatez comunicativa, porém um tema mais espinhoso no momento pode criar certa distância comunicativa, que provoca mudança brusca na comunicação. Sendo assim, aquela interação, em que não se esperavam táticas atenuadoras, pode exigir elementos de atenuação, com a finalidade de manter o equilíbrio da interação. Para tanto, observemos os exemplos a seguir, envolvendo a forma verbal futuro do pretérito no português do Brasil.

(10) Inf.: (...) porque se não tivesse o servente que varresse a rua não tivesse o servente que varresse a repartição não seria:: quem é que iria varrer a repartição? seria o chefe da seção? Inquérito 8 NURC/RS p.60 
Neste caso, a forma condicional pode ser considerada como normal ou convencional, pois se trata do processo consecuctio temporum, isto é, trata-se de uma forma de concordância temporal convencional no português do Brasil. Explicando: a forma tivesse (imperfeito do subjuntivo) concorda, naturalmente, com o futuro do pretérito seria. No modelo gramatical do português do Brasil, não poderia ser outra a concordância de tempos verbais. Sendo assim, neste exemplo, não há por que analisar como um recurso de atenuação. O contexto interacional imediato não nos conduz ao equívoco.

(11) Doc.: você sabe que há vários divertimentos noturnos... não?

Inf.: certo...

Doc.: poderia enumerar?... várias opções de divertimento...

Inquérito 12 NURC/RJ p.20

Neste caso, a forma "poderia" é uma forma verbal utilizada para desfocalizar o eixo temporal e modal, com a finalidade de expressar o pedido de uma forma mais suave. Para não soar impositivo, o entrevistador utiliza a forma "poderia" com o intuito de mitigar a força ilocutiva do pedido para enumerar as várias opções de divertimento disponíveis.

(12) Doc.: eu gostaria que você faLAsse... a respeito da sua casa eu sei que você... lutou MUlto para construir esta casa então eu gostaria que você fala::sse... o que você quiSEsse a respeito do da Ca::sa... como você percebe ()

(Inq. 004, NURC/Recife, p.43)

Neste exemplo, o documentador inicia o turno atenuando o ato diretivo, pois, em vez de pedir, diretamente, que o informante fale a respeito da casa que construiu, faz o pedido de uma forma atenuada, por meio do futuro do pretérito (condicional) gostaria. Um ato diretivo no futuro do pretérito ou condicional funciona como atenuador de um ato impositivo, pois estabelece certo distanciamento entre locutor e interlocutor e, nesse sentido, se há maior distância interpessoal, há demonstração de atitude cortês do locutor. Além disso, usa, também, a estratégia de preservar a face positiva do interlocutor, salientando o esforço que foi feito. Utiliza, ademais, uma estratégia de cortesia negativa, ao atenuar a imposição que está sendo realizada, pois o enunciado "gostaria que você fala::sse... o que quiSEsse" minimiza a imposição feita: fale a respeito da construção de sua casa.

(13) Doc.: eu gostaria que você faLAsse... a respeito da sua casa eu sei que você... lutou MUlto para construir esta casa então eu gostaria que você fala::sse... o que você quiSEsse a respeito do da Ca::sa... como você percebe ( )

(Inq. 004, NURC/Recife, p.43)

Neste exemplo, o documentador inicia o turno atenuando o ato diretivo, pois, em vez de pedir, diretamente, que o informante fale a respeito da casa que construiu, faz o pedido de uma forma atenuada, por meio do futuro do pretérito (condicional) gostaria. Um ato diretivo no futuro do pretérito ou condicional funciona como atenuante de um ato impositivo, pois estabelece certo distanciamento entre locutor e interlocutor e, nesse sentido, se há maior distância interpessoal, há demonstração de atitude cortês do locutor. Além disso, usa, também, a estratégia de preservar a face positiva do interlocutor, salientando o esforço que foi feito. Utiliza, também, uma estratégia de cortesia negativa, ao atenuar a imposição que está 
sendo realizada, pois o enunciado "gostaria que você fala::sse... o que quiSEsse" minimiza a imposição feita: fale a respeito da construção de sua casa.

(14) Doc.: Então nós vamos conversar sobre ensino, né? Nós vamos começar assim... Como é que está... eh... estruturado o ensino, quais os níveis de ensino que nós temos aqui... eh... entre nós? Pode começar desde o comecinho e tal... Não se preocupe muito com a técnica não, porque a gente...

(Inq.231, NURC/Salvador, p.150)

Nota-se que o documentador está preocupado em ser bem claro em relação à pergunta que será enunciada, tanto é que demonstra certa hesitação. Dessa forma, busca deixar o informante bem à vontade: "Pode começar" revela o emprego de um verbo modal de possibilidade; "Não se preocupe muito com a técnica não" revela o emprego de um típico recurso de atenuação, o diminutivo, em "comecinho", que, de certa forma, mascara a questão técnica, minimizando o esforço que será feito pelo interlocutor.

(15) Doc.: Bom, dona M., então, nós vamos conversar sobre... eh... digamos assim, os... quais são os principais produtos que, em geral, o Brasil exporta? Podemos começar pela Bahia. (rindo) A conversa não é muito de... de Serviço Social, mas...

Inf.: É... está...

Doc.: O que é que a senhora, em geral... o que é que a gente ouve falar aí de coisas que a Bahia exporta? (Inq.356, NURC/Salvador, p.259)

O exemplo em questão traz vários procedimentos de atenuação. Inicialmente, o documentador usa tratamentos respeitosos, preservando a face positiva do interlocutor, primeiro dona M. e, depois, a senhora. Em seguida, aparece o nós inclusivo. É preciso lembrar que será a informante que deverá falar sobre o assunto em questão, mas o documentador também se envolve na interação, dizendo que "eles" (documentador + informante) conversarão sobre tal assunto. Há, também, o que Fraser chama de hedges e Marcuschi (1986:74) denomina evasivas, como o "digamos assim". O "digamos assim" modifica a força da pergunta que será enunciada, atenuando a conotação impositiva que pode transparecer no ato. Rosa (1992:50) salienta que esses marcadores, acompanhados de verbos declarativos, nem sempre são atenuadores, pois podem introduzir paráfrases, como ocorre no exemplo 6. Neste caso, tudo leva a crer que se trata de um procedimento de atenuação.

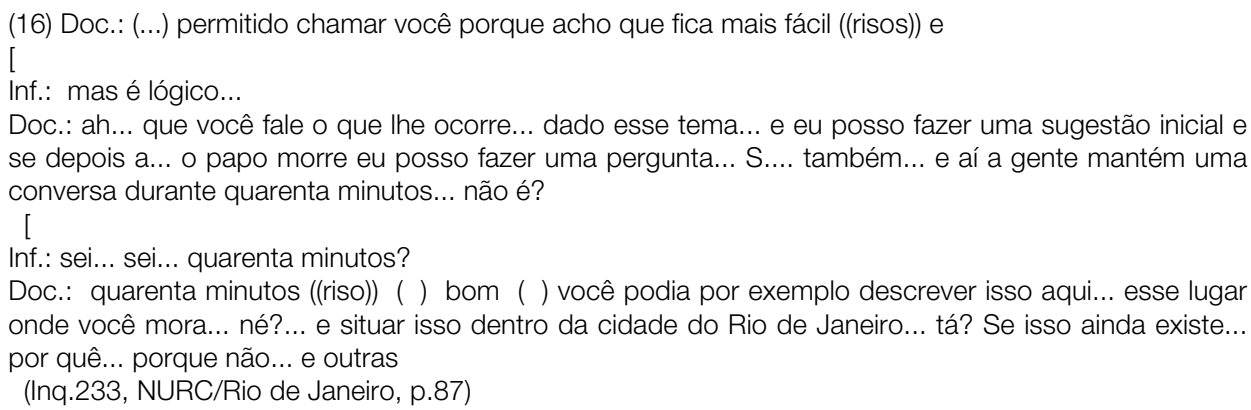

Neste exemplo, percebe-se, claramente, que o documentador procura eliminar aspectos que possam dificultar a interação, por isso pede permissão para utilizar uma forma de tratamento mais cordial, "você", a fim de deixá-los mais à vontade. O informante concorda com a 
colocação do documentador e este, de uma forma que não ameace a face de seu interlocutor, busca estabelecer o que será feito naquela interação. De antemão, diz que fará uma sugestão inicial e, caso o tópico não avance, voltará a intervir por meio de uma pergunta. Dessa forma, as perguntas podem ser feitas, com a finalidade de alimentar o tópico e a interação e, assim, não representarão qualquer ameaça à face dos interactantes. Também, esclarece que a interação terá a duração de quarenta minutos, o que leva o informante a ficar admirado e repetir o segmento, com uma entonação interrogativa. Repare-se que esse seria um momento em que o equilíbrio da interação poderia ser rompido, pois o informante poderia não concordar com as regras estabelecidas, no entanto os risos servem para atenuar a inflexibilidade da regra de duração da conversa.

(17) Doc.: seu N.... nós gostaríamos que o senhor contasse pra gente... todo seu ciclo de vida... desde...a inFÂNcia... adolesCÊNcia maturidade época de casaMENto... como é que FOI... como é que o senhor conheceu sua esposa como foi o casaMEN::to ahn:: a sua adolescência enfim tudo que o senhor podia contar pra gente assim de interessante nós gostaríamos que o senhor contasse por favor...

(Inq.208, NURC/São Paulo, p.89)

Trata-se de um exemplo com vários procedimentos de atenuação. Em primeiro lugar, há preocupação em preservar a face positiva do informante, tratando-o por "Seu N." e "o senhor". Em segundo, o emprego do nós inclusivo, que dá um contorno de distância. Em terceiro, o verbo "gostaríamos", no futuro do pretérito ou condicional. O uso estratégico do condicional provoca um distanciamento entre o conteúdo da proposição e o falante. Dado que o futuro do pretérito de cortesia empregado em uma recusa produz efeitos mitigadores, e seguindo as observações de Haverkate (1994:145), é preferível utilizar o termo condicional de mitigação, já que o caráter atenuador do condicional conota a noção de cortesia. Com o fim de atenuar os efeitos negativos de um ato que ameaça a imagem, o locutor seleciona o futuro do pretérito para evitar um confronto direto com o interlocutor, enfatizando o respeito social que ditam as normas sociais da sociedade brasileira. Com o mesmo efeito, é empregado o verbo poder ("podia"). Esse emprego de poder insere-se no que se costuma chamar de marcadores de possibilidade epistêmica, que permitem flexibilizar a decisão do interlocutor, ao proporcionar a alternativa de negar o pedido, sem ameaçar a face. Em quarto lugar, aparece um conhecido marcador de cortesia social, "por favor", reforçado por outros elementos: "nós", "gostaríamos", "senhor".

(18) Doc.: o que que o senhor acha do salão de beleza para homens?...

Inf.: olha... salão de beleza para homem... isso é um negócio meio afrescalhado... eu eu eu não não iria no salão de beleza pra homens agora cortar o cabelo... ah:: decentemente eu eu acho eu acho muito bom tem algumas coisas que são inovações boas mas esse negócio de salão de beleza pra homem eh: é meio afrescalhado.. Inquérito 8 NURC/RS

A Documentadora faz uma pergunta ao Informante a respeito da opinião sobre salão de beleza para homens. Como o Informante não esconde sua opinião crítica a respeito do assunto, busca atenuar, com a finalidade de diminuir a força ilocutiva de seus atos. Para isso, emprega a forma "meio", e "eu acho" repetida; "iria". 


\section{CONCLUSÕES}

Como já ficou claro no início deste trabalho, utilizamos, como corpus, inquéritos, do tipo DID (Diálogos entre Informante e Documentador). Não se trata de contextos que envolvam conflitos, no entanto é preciso salientar que, tanto nos atos diretivos do Documentador, quanto nas respostas dos Informantes, há momentos em que os interlocutores buscam a utilização das táticas atenuadoras, especialmente quando a autoimagem é colocada em risco ou a imagem do interlocutor pode ser ameaçada.

Além do mais, nosso objetivo básico era desmitificar o estudo sobre atenuação e evitar generalizações, como afirmar que, quando há uma forma diminutiva, haverá atenuação ou, quando encontrarmos a forma condicional, será sinal de que o ato de fala estará atenuado.

Entendemos que a aplicação de duas regras básicas encontradas na Ficha Técnica do Projeto ES.POR.ATENUACIÓN será muito útil, pois evitará equívocos na análise. São elas: evitar generalizações e utilização do contexto interacional imediato. É importante ressalvar que elas não aparecem na Ficha como regras ou como vantagens, no entanto, a utilização desses dois procedimentos estão ora explícitos, ora implícitos ao longo das exposições teóricas.

Dessa forma, buscamos contribuir, ainda de maneira superficial, para a análise dos procedimentos atenuadores no português do Brasil.

\section{REFERÊNCIAS}

ALBELDA, Marta ET al.(2014). Ficha metodológica para el análisis pragmático de la atenuación en corpus discursivos del español: ES.POR.ATENUACIÓN. Oralia, 1-44.

BRIZ, Antonio (1994). La atenuación en la conversación coloquial. Una categoria pragmática. In: CORTÉS RODRIGUEZ, J. (Ed.). EI español coloquial: Actas del I Simposio sobre análisis del discurso oral. Almería: Universidad de Almería.

BRIZ, Antonio (2005). Eficacia, imagen social e imagen de cortesia. Naturaleza de la estratégia atenuadora en la conversación cotidiana española. Estudios de la (des) cortesía en español. Buenos Aires: Dunken.

BRIZ, Antonio (2007). Para un análisis semántico, pragmático y sociopragmático de la cortesía atenuadora en España y América. Lingüística Española Actual: XXIX/1:5-44.

BRIZ, Antonio (2013). A atenuação e os atenuadores: estratégias e táticas. Tradução para o português de Luiz Antonio da Silva, Adriana Marcelle de
Andrade e Ramiro C. H. Caggiano Blanco. Linha d'água, 26(2):281-314.

BROWN, Penélope e LEVINSON, Stephen (1987). Politeness: some universals in language use. Cambridge: Cambridge University Press.

CALLOU, Dinah e LOPES, Célia R. (Orgs.) (1993). A linguagem falada culta na cidade do Rio de Janeiro: materiais para seu estudo. Rio de Janeiro: Universidade Federal do Rio de Janeiro.

FRASER, Bruce (1980). Conversacional mitigation. Journal of Pragmatics, 4:219-235.

GOFFMAN, Ervin (1970). Ritual de la interacción. Buenos Aires: Tiempo Contemporáneo.

HILGERT, José Gaston (Org.) (1997). A linguagem falada culta na cidade do Rio de Janeiro: materiais para seu estudo. Passo Fundo: Universidade de Passo Fundo.

MEYER-HERMANN, Reinhard (1984). Formas de atenuação no ensino do Português como língua estrangeira. In: CARVALHO, J. Herculano G. de e SCHIMIDT- RADEFELDT, Jurgen (Eds.). Estudos de Linguística Portuguesa. Coimbra: Coimbra Editora, p.173-194. 
MOTTA, Jacyra e ROLLEMBERG, Vera (Orgs.) (1994). A linguagem falada culta na cidade de Salvador: materiais para seu estudo. Salvador: Universidade Federal da Bahia.

PUGA LARRAÍN, Juana (1997). La atenuación en el castellano de Chile: un enfoque pragmalingüístico. Valencia: Universitat de Valencia.

ROSA, Margaret (1992). Marcadores de atenuação. São Paulo: Contexto.
SÁ et alii (Orgs.) (1996). A linguagem falada culta na cidade do Recife: materiais para seu estudo. Recife: Universidade Federal de Pernambuco.

SEARLE, John R. (1976). A taxonomy of illocutionary acts. Linguistic Agency University of Trier.

SILVA, Luiz Antônio da (2008). Formas de tratamento e cortesia. In: PRETI, Dino (Org.) (2008). Cortesia verbal. São Paulo: Humanitas, p.157-192.

SOARES, Maria da Conceição P. (1996). Modificação de actos ilocutórios, em Português. Dissertação de Mestrado defendida na Universidade do Porto. 